\title{
Cambios ambientales en el desierto de Sechura y alternativas para su aprovechamiento
}

\author{
Environmental change in the desert Sechura and alternatives for its use
}

\author{
Jaime Deza Rivasplata, Juan Tume Ruiz ${ }^{*}$, Juan Alarcón Delgado ${ }^{* *}$
}

http://dx.doi.org/10.21503/CienciayDesarrollo.2010.v12.02

\section{RESUMEN}

Desde el año 2004 se observa en la margen izquierda del desierto de Sechura la presencia de una laguna desconocida ubicada en los paralelos $05^{\circ} 35^{\prime}$ latitud sur y $80^{\circ} 34^{\prime}$ longitud oeste y a $4 \mathrm{~m}$ de altitud, en lo que la Carta Nacional del Instituto Geográfico Nacional (IGN ) denomina como la depresión Bayóvar, por tener este sitio una profundidad de 37 metros bajo el nivel de mar.

Los estudios y monitoreo desde el año 2004, con una frecuencia mensual durante los años 2008 y 2009, indican que esta tiene un ciclo periódico anual de extensión $\left(200 \mathrm{~km}^{2}\right)$ y reducción $\left(60 \mathrm{~km}^{2}\right)$ de su superficie, el que ha permitido el desarrollo de una flora cuyo biotipo dominante es el algarrobo (Prosopis julyflora), en una extensión de 800 kilómetros cuadrados con una densidad de 3200 plantones por hectárea.

En la laguna se puede desarrollar una acuicultura apropiada de especies eurihalinas así como el manejo sostenible del bosque en beneficio de las comunidades locales.

Palabras clave: boleo (técnica de sembrar esparciendo manualmente los granos de semilla al aire), limnologia (estudio de los ecosistemas acuáticos), eurihalinos (seres acuáticos capaces de vivir en un amplio rango de concentración de sales).

\section{ABSTRACT}

Since 2004 is shown in the left margin of the Sechura desert the presence of an unknown lagoon that is located on the parallels $05^{\circ} 35^{\prime}$ south and latitude $80^{\circ} 34^{\prime}$ west longitude and $4 \mathrm{~m}$, in what the National Letter of the Geographical National (IGN) Institute denominates as the depression Bayóvar, for having this site to a depth of 37 meters below sea level.

Studies and monitoring since 2004 and on a monthly since January of this year indicate that this is a regular annual cycle of extension $\left(200 \mathrm{~km}^{2}\right)$ and a reduction $\left(60 \mathrm{~km}^{2}\right)$ in size and has allowed the development of a flora and whose dominant biotype algarrobo (Prosopis julyflora) in an extension of 800 square kilometers with a density of 3200 plants per hectare.

In the lagoon may develop appropriate aquaculture euryhaline species and the sustainable management of forests for the benefit of local communities.

Key words: throw, limnology, euryhaline.

\footnotetext{
*Antropólogo, arqueólogo. Director de Investigación de la Universidad Alas Peruanas. e-mail: jaimedeza@@hotmail.com

"Ingeniero pesquero, docente de la Universidad Alas Peruanas y de la Universidad Nacional de Piura. e-mail: delfin_jtr@hotmail.com

*** Director de la EAP de Ingeniería Ambiental de la UAP, Piura. e-mail: j_alarcon@uap.edu.pe
} 


\section{INTRODUCCIÓN}

Lo que se conoce como desierto de Sechura, en Piura, es el espacio de mayor aridez comprendido entre el paralelo de Bayóvar y el de Chulliyache, y desde el litoral hasta cerca de la carretera Panamericana en Olmos, más precisamente entre los $5^{\circ} 33^{\prime}$ a $5^{\circ} 48^{\prime}$ de Latitud Sur y los 80'32' a $80^{\circ} 42^{\prime}$ de Longitud Oeste. Esta zona ha iniciado un cambio ambiental a partir del año 1984 , y con mayor intensidad después del año 1998, como consecuencia de los eventos El niño. Se observa un proceso de forestación natural, y en algunos sectores cercanos a la carretera Panamericana incluso se siembran "al boleo" semillas de algarrobo (Prosopis julyflora) y casuarinas (Casuarina equisetifolia), desde el aire. En el año 2004, el cambio se acelera haciéndose más evidente: se comienza a llenar de agua la depresión Bayóvar, una fosa de $187 \mathrm{~km}^{2}$ de área y $37 \mathrm{~m}$ de profundidad que se ha convertido en el sector de mayor profundidad en la superficie del país. (Instituto Geográfico Nacional, 1995).

La nueva laguna es desconocida oficialmente, al punto que no se ubica en la Carta Nacional (1995). El Instituto Geológico Minero y Metalúrgico (INGEMMET) denomina al área como de "arenas húmedas" (Carta Geológica Nacional, Julio Caldas y otros, 1980). El Gobierno Regional de Piura en su Plan estratégico de la babía de Sechura y la isla de Lobos de Tierra - diagnóstico (enero de 2005), elaborado por la Gerencia Regional de Manejo Integrado de Recursos de la Zona Marino-Costera de Piura, no la menciona, lo que sí hace con las lagunas Ramón y Napique. La monografía sobre la provincia de Sechura $D e-$ claración y plan de acción ambiental de la provincia de Sechura, editada por el Municipio Provincial (2005), también la ignora. En consecuencia, es conocida solo por algunos habitantes del caserío Mala Vida que concurren a pescar en ella. Finalmente, los resultados de las exploraciones del Seminario de Arqueología del Instituto Riva Agüero, de la Universidad Católica del Perú, pu- blicadas en un texto integral por el arquitecto Carlos Milla (1989), Inventario de un desierto, tampoco la registran, y es que en aquel entonces el desierto de Sechura presentaba la más completa sequedad.

El nuevo escenario se presenta como un bosque intenso con 3200 plantones de algarrobo de diferentes edades en algunos sectores, mientras al centro, como un espejo de agua de hasta $200 \mathrm{~km}^{2}$, aparece la laguna formada por las filtraciones del manto acuífero y el ingreso de un delgado cauce del río Piura.

El otrora desierto ha desaparecido para dar paso a una laguna en medio de un bosque de $800 \mathrm{~km}^{2}$, con una rica y variada fauna de aves y peces.

Como debe ser, el trabajo tiene como objetivo general estudiar las características de la laguna, su influencia en los cambios ambientales del lugar y las alternativas para su aprovechamiento.

\section{Objetivos especificos}

a. Conocer los orígenes o causas de la formación de la laguna.

b. Áreas y cronología de extensión y reducción del espejo de agua.

c. Características limnológicas del agua y su relación cronológica.

d. Volúmenes de agua y frecuencias de reducción e incremento.

e. Fauna interna y proyecciones de su volumen.

f. Fauna que se desarrolla al exterior de la laguna.

g. Flora y áreas de extensión alrededor de la laguna.

h. Alternativas para un manejo sostenible del bosque naciente.

\section{Hipótesis}

H1. El levantamiento del manto acuífero como consecuencia del evento El Niño 1998 y el actual 
ingreso de aguas del río Piura serían las causas de la formación de la nueva laguna.

H2. Si las características de la laguna son óptimas, permitirán la ejecución de un proyecto de desarrollo sostenible de especies de fauna y flora.

\section{Metodología de trabajo}

a. Exploraciones de campo directas.

b. Monitoreos limnológicos mensuales de la laguna.

c. Mediciones mensuales de la superficie del espejo de agua.

d. Mediciones de volúmenes de agua.

e. Identificación de especies eurihalinas y de fauna externa.

f. Censos anuales y monitoreo de los estratos arbustivos.

g. Análisis de suelos en los sectores de arenas húmedas.

\section{RESULTADOS}

\section{Estratos vegetales}

El área general de estudio se inicia en el paralelo de Bayóvar hasta el de Chulliyache $\left(5^{\circ} 33^{\prime}\right.$ - $5^{\circ} 48^{\prime}$ Latitud Sur y $80^{\circ} 32^{\prime}-80^{\circ} 42^{\prime}$ Longitud Oeste), y posee cuatro estratos vegetales bien definidos. Está poblada por el algarrobo, que es el biotipo dominante, registrándose hasta 3200 plantones en cada hectárea de arenal; y nos señala cuatro momentos consecutivos de germinación, cuyo resultado es la población actual de plantones surgidos de un proceso de germinación natural, los mismos que han logrado sobrevivir.

Las frecuencias en cada estrato de algarrobos por hectárea, en líneas generales, son las siguientes (diciembre 2009):

a. Estrato de 0,80 m de 2 años de edad: 2400 plantones.

b. Estrato de 1,60 $\mathrm{m}$ de 3 a 4 años de edad: 755 plantones.

c. Estrato de 3 a $4 \mathrm{~m}$ de 5 a 6 años de edad: 33 plantones.

d. Estrato de $7 \mathrm{~m}$ de 10 años de edad a más: 9 plantones, y 30 plantones de zapote (Capparis angulata).

Esta área tiene una extensión (de mayor concentración vegetal) de $40 \mathrm{~km}$ de ancho (de norte a sur) por $20 \mathrm{~km}$ de largo (de este a oeste), lo que hace una cubierta verde de $800 \mathrm{~km}^{2}$ (80 000 hectáreas) de bosque.

\section{La laguna}

Al centro, como un espejo del cielo, la laguna actual, con siete años de vida (2010), desciende y asciende de nivel, creciendo anualmente por el ingreso del río Piura y el ascenso del manto acuífero que cada vez aflora más a la superficie.

Esta laguna tiene, en su momento de mayor extensión, en el mes de marzo, un perfil lenticular que abarca en promedio un área de 20 $\mathrm{km}$ por $10 \mathrm{~km}\left(200 \mathrm{~km}^{2}\right.$ de espejo, considerando islotes y curvas por diferencias de altitudes en las márgenes, $5^{\circ} 35^{\prime}$ a $5^{\circ} 47^{\prime}$ Latitud Sur $/ 80^{\circ} 34^{\prime}$ $18^{\prime \prime}$ a $80^{\circ} 41^{\prime}$ Longitud Oeste, y $4 \mathrm{~m}$ de altitud). En el mes de noviembre, llega a los $10 \mathrm{~km}$ de largo por $6 \mathrm{~km}$ de ancho (5०39' $30^{\prime \prime}$ a 5० 44 ' $35^{\prime \prime}$ / $80^{\circ} 36^{\prime}$ a $80^{\circ} 39^{\prime}$ ), conservándose la parte de mayor profundidad de la fosa.

\section{Aspectos limnológicos}

\section{Temperatura del aire}

La temperatura del aire se registró con un termómetro de mercurio, dos veces al día (a las 06:00 y a las 18:00 horas). De acuerdo a los registros, el mes que presenta menor temperatura es el de agosto, con un valor de $18,6{ }^{\circ} \mathrm{C}$. Las temperaturas aumentan a medida que se acerca la estación de verano, llegando a su máximo valor en el mes de febrero, con $30^{\circ} \mathrm{C}$. 


\section{Temperatura del agua}

La temperatura del agua se registró dos veces diarias (6:00 y 18:00 horas), no encontrándose diferencia significativa en el horario diario, pero sí durante el mes de agosto, cuando se registran las temperaturas más bajas del año $\left(19^{\circ} \mathrm{C}\right.$ para el agua). A partir de septiembre, sin embargo, comienza a elevarse la temperatura a medida que las horas diarias de sol van en aumento y la estación de verano va llegando, registrándose en el mes de febrero $28^{\circ} \mathrm{C}$ de temperatura en el agua.

\section{Transparencia}

Los valores de transparencia oscilan durante noviembre, cuando se alcanza la máxima regresión de la laguna, entre 40 y $45 \mathrm{~cm}$. En marzo se presenta el momento de máxima extensión $(60 \mathrm{~cm})$, demostrando una buena productividad planctónica. Cabe indicar que los valores máximos se dan durante el verano.
Tabla 1. Análisis del agua de la laguna

$\begin{array}{llr}\mathrm{pH} & & 5,73 \\ \text { C.E. } & \mathrm{d} S / \mathrm{m} & 6,23 \\ \text { Calcio } & \mathrm{me} / 1 & 18,90 \\ \text { Magnesio } & \mathrm{me} / \mathrm{l} & 1,40 \\ \text { Potasio } & \mathrm{me} / 1 & 1,04 \\ \text { Sodio } & \mathrm{me} / 1 & 55,65 \\ & & \\ \text { Nitratos } & \mathrm{me} / 1 & 0,01 \\ \text { Carbonatos } & \mathrm{me} / 1 & 0,00 \\ \text { Bicarbonatos } & \mathrm{me} / 1 & 1,64 \\ \text { Sulfatos } & \mathrm{me} / 1 & 3,95 \\ \text { Cloruros } & \mathrm{me} / 1 & 70,00 \\ & & \\ \text { Sodio } & \% & 72,28 \\ \text { RAS } & & 17,46 \\ \text { Boro } & \mathrm{ppm} & 0,39 \\ \text { Clasificación } & & \mathrm{F}, \mathrm{C}\end{array}$

Resultado de los análisis del agua de la laguna en el Laboratorio de Análisis de Suelo, Plantas, Aguas y Fertilizantes de la Universidad Nacional Agraria La Molina. (Marzo de 2009.)

Tabla 2. Evaluación física de la laguna

\begin{tabular}{|c|c|c|c|}
\hline Datos & Punto \# 1 & Punto \# 2 & Punto \# 3 \\
\hline Sur & $05^{\circ} 43^{\prime} 00^{\prime \prime}$ & $05^{\circ} 43^{\prime} 02^{\prime \prime}$ & $05^{\circ} 42^{\prime} 45,9^{\prime \prime}$ \\
\hline Oeste & $80^{\circ} 35^{\prime} 24,9^{\prime \prime}$ & $80^{\circ} 35^{\prime} 25,1^{\prime \prime}$ & $80^{\circ} 35^{\prime} 26,7^{\prime \prime}$ \\
\hline Altura & $12 \mathrm{msnm}$ & 11 & 14 \\
\hline $\mathrm{T}^{\circ}$ & $19^{\circ}$ & $20^{\circ}$ & $20^{\circ}$ \\
\hline $\mathrm{PH}$ & 8.6 & 8.89 & 8 \\
\hline Oxigeno & 10.4 & 11,2 & 10,5 \\
\hline Disco Secchi & $14 \mathrm{~cm}$ & $16 \mathrm{~cm}$ & $16 \mathrm{~cm}$ \\
\hline Salinidad & 0,2 & 0,2 & 0.2 \\
\hline \multirow[t]{3}{*}{ Profundidad } & $40 \mathrm{~cm}$ & $44 \mathrm{~cm}$ & $40 \mathrm{~cm}$ \\
\hline & Distancia P\#1 a P\# 2 & & Distancia P\#2 a P\#3 \\
\hline & $152 m$ & & $503 \mathrm{~m}$ \\
\hline
\end{tabular}

P 2

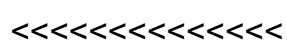




\section{Extensión de la laguna}

\section{Marzo (2010)}

\section{Extremo norte:}

$\begin{array}{llll}4 \mathrm{~m} \text { de altitud } 05^{\circ} 35^{\prime} \text { Lat. Sur y } & 080^{\circ} 34^{\prime} 18^{\prime \prime} & \text { Long. oeste a } 080^{\circ} 41^{\prime} \\ 4 \mathrm{~m} & 05^{\circ} 42^{\prime} 57,4^{\prime \prime} & 080^{\circ} 35^{\prime} 26^{\prime \prime} & \text { a } 080^{\circ} 41^{\prime} \\ 4 \mathrm{~m} & 05^{\circ} 42^{\prime} 55,9^{\prime \prime} & 080^{\circ} 35^{\prime} 02,6^{\prime \prime} & \text { a } 080^{\circ} 41^{\prime} \\ 4 \mathrm{~m} & 05^{\circ} 42^{\prime} 57,4^{\prime \prime} & 080^{\circ} 35^{\prime} 02,3^{\prime \prime} & \text { a } 080^{\circ} 41^{\prime} \\ 4 \mathrm{~m} & 05^{\circ} 42^{\prime} 48,8^{\prime \prime} & 080^{\circ} 35^{\prime} 26^{\prime \prime} & \text { a } 080^{\circ} 41^{\prime}\end{array}$

\section{Extremo sur}
$7 \mathrm{~m}$
$05^{\circ} 47^{\prime}$
$080^{\circ} 35^{\prime}$
a $080^{\circ} 41^{\prime}$

Dimensiones (máximas):

Largo: $25 \mathrm{~km}$ sur - norte

Ancho: $16 \mathrm{~km}$ este - oeste

Espejo de agua: $200 \mathrm{~km}^{2}$ considerando curvas, islotes.

Profundidad: $0,60 \mathrm{~m}$ a 30 metros de la orilla.

Transparencia: Bastante clara y nítida. A 1 metro de profundidad se observa el fondo de arena endurecida.

Noviembre (2009)

Extremo norte
$4 \mathrm{~m}$
$05^{\circ} 39^{\prime} 30^{\prime \prime}$
$080^{\circ} 36^{\prime} 16^{\prime \prime}$
a $080^{\circ} 39^{\prime} 16^{\prime \prime}$

Extremo sur

$6 \mathrm{~m}$

$05^{\circ} 44^{\prime} 35^{\prime \prime} \quad 080^{\circ} 36^{\prime}$

a $080^{\circ} 39^{\prime}$

Dimensiones (mínimas):

Largo: $10 \mathrm{~km}$ sur - norte

Ancho: $6 \mathrm{~km}$ este - oeste

\section{Salinidad}

La salinidad se debe a la influencia de las aguas del río Piura y a las precipitaciones fluviales. El valor más bajo se registra en el mes de marzo, para luego incrementarse a un valor máximo en el mes de octubre $(0,2 \%)$.

\section{$\mathrm{pH}$}

$\mathrm{El} \mathrm{pH}$ registrado durante los primeros meses (marzo) fue de 5,73, y luego ha ido aumentando en los siguientes meses, hasta alcanzar su máximo valor de 8,89 en el mes de agosto.

\section{Oxígeno disuelto}

Se observa que la concentración de oxígeno se ha venido incrementando ligeramente mes a mes, desde un valor de 6,3 o/oo en marzo del año 2009 , hasta 10,5 o/oo en octubre de este año (2010). 
Tabla 04. Características físico químicas de la Laguna (julio 2008 a junio-2009)

\begin{tabular}{l|l|l|l|l|l|l} 
MESES & $\mathrm{T}^{\circ}$ Aire $\left({ }^{\circ} \mathrm{C}\right)$ & $\mathrm{T}^{\circ}$ Agua $\left({ }^{\circ} \mathrm{C}\right)$ & Transp. $(\mathrm{cm})$. & Salinidad $(\mathrm{o} / \mathrm{oo})$ & Oxigeno $(\mathrm{o} / \mathrm{oo})$ & $\mathrm{pH}$ \\
\hline Julio & 20,3 & 22,3 & 33,2 & 4 & 6,3 & 7,5 \\
\hline Agosto & 18,6 & 20,5 & 31,2 & 4 & 6,4 & 7,5 \\
\hline Septiembre & 19,5 & 21,1 & 31,0 & 6 & 6,5 & 7,5 \\
\hline Octubre & 20,5 & 22,2 & 31,0 & 9 & 7,2 & 7,5 \\
\hline Noviembre & 28,5 & 26,0 & 32,0 & 9 & 8,0 & 8,0 \\
\hline Diciembre & 29,0 & 27,5 & 33,0 & 10 & 8,3 & 8,0 \\
\hline Enero & 29.5 & 27,5 & 32,0 & 10 & 8,5 & 8,0 \\
\hline Febrero & 30,0 & 28,0 & 35,0 & 11 & 9,0 & 8,5 \\
\hline Marzo & 29.5 & 27,8 & 32,0 & 12 & 9,4 & 8,75 \\
\hline Abril & 25.2 & 22,3 & 34,3 & 14 & 9,4 & 7,25 \\
\hline Mayo & 25,0 & 21,0 & 34,0 & 14 & 9,5 & 7,0 \\
\hline Junio & 23,0 & 22,0 & 34,0 & 14 & 9,6 & 7,0 \\
\hline
\end{tabular}

\section{Fauna}

El fondo de la laguna es de arena, limpio y endurecido, con agua cristalina y dulce al paladar que permite la presencia de peces pequeños como la lisa (Mugil cephalus), tilapia (Oreochromis sp.), carpa (Cyprinus carpio), monenque (Dormitator latiforns), robalo (Centropomus sp.), life (Trichomycterus sp.), guppy (Poecilia reticulata), almeja de agua dulce (Anodonta anatina), camarón de río (Criphiops caementarius) langostino blanco (Panaeus vannamei).

En las orillas se ven flamencos (Phoenicopterus chilensis), garzas (Ardea alba), garcita blanca (Egretta thula), gaviota dominicana ( $L a-$ rus dominicanus), gaviota peruana (Larus velcheri), gaviota gris (Larus cirraophalus), piqueros (Sula variegata), pardelas (Procellariidae sp.), cleos (Sterna sandvicensis), cigüeña (Mycteria americana), cigüeñuela, perrito, niña (Himantopus mexicanus), halcón (Falco peregrinus) caracara (Caracara cheriway), gavilán bicolor (Accipiter bicolor), gavilán negro (Buteogallus urubitinga), aguilucho (Buteo polyosoma), chilalo (Furnarius leucopus), tordo (Molothrus bonariensis), putilla de pecho rojo (Pyrocephalus rubinus), golondrina tijereta (Hirundo rustica), tirano tropical, pepite (Tyrannus melancholicus), pelícano peruano (Pelecanus thagus), turtupilin (Pyrocephalus rubino), sarapito trinador (Numenius phareopus), pato colorado (Anas cyanoptera), pato morado (Netta erythropthalma), pato de pico blanco (Fulica atra), cormorán (Phalacrocorax brasilianus), gallareta andina (Fulica ardesiaca), zorro (Psudalopex sechurae), gato de monte (Oncifelis colocolo), venado (Odocoilesus virginianus), cabra salvaje "alzada" (Capra hircus), cañán azulejo (Dicrodon guttulatum), capón común (Microlophus occipitales), lagartija (Ameiva edracantha), iguana (Callopistes flavipuntatus), sapo cololo (Bufonidaesp.).

Por las consideraciones ambientales y de fauna migratoria, el lugar tiene suficientes recursos para ser considerado oficialmente como Santuario Natural.

\section{Recurso hidrico}

Casi al centro del desierto ( $5^{\circ} 40^{\prime}$ Latitud Sur, $80^{\circ} 41^{\prime}$ Longitud Oeste), se registra una notable depresión que ocupa un área de 185 $\mathrm{km}^{2}$ aproximadamente, y alcanza una máxima profundidad de $37 \mathrm{~m}$ bajo el nivel del mar. (Fuente: Instituto Geográfico Nacional, 1995).

En esta fosa se observan huellas de un antiguo fondo marino de épocas previas al máximo levantamiento de los Andes (Terciario), tal como se registra en otros lugares costeños, siendo el más importante el Tablazo de Ica-Nasca. Aquí, al igual 
que en Ica, se registraron fósiles marinos, en especial de dientes de tiburón; pues bien, esta fosa ha sido ocupada por el agua del manto que se desplaza hacia la depresión, lo que nos permite suponer que el paisaje que en la actualidad nos causa sorpresa se ha repetido en anteriores oportunidades, aunque no sabemos con qué ritmo.

Todo indica que el último ciclo debió iniciarse con el evento El Niño. Durante el año 1984, y en 1998, se formó, como está comprobado, la laguna mal llamada "La Niña", la cual al secarse por filtraciones y evaporación (a los 13 meses), trajo como consecuencia que se elevara el manto acuífero, permitiendo el enraizamiento de los plantones que brotaron en sus zonas marginales. Más tarde, la acumulación de agua del río y el manto que se eleva reteniéndola y retrasando la filtración permitieron la formación de la "nueva" laguna de Sechura, que en marzo se convierte en la segunda laguna de nuestro país, por su tamaño.

Tenemos entonces una laguna con 200 millones de metros cúbicos de agua dulce apta para el riego (conservadoramente), a finales de verano. En noviembre, su volumen llega a 60 millones de metros cúbicos (considerando que subsiste en la parte de mayor profundidad de la depresión).

Represada de manera natural, esta laguna equivale a la represa de Poechos, dos veces más que la de San Lorenzo (Piura), parte de Tinajones (Lambayeque) y un tercio de la represa de Gallito Ciego, del valle Jequetepeque.

El nacimiento de los algarrobos que cubren toda la extensión del bosque es un misterio. Sabemos que para que una semilla de algarrobo germine, por poseer un tegumento (cáscara dura), debe pasar por un tratamiento pregerminativo, el mismo que recibe al pasar la semilla por el tracto digestivo, donde sufre la acción de los jugos gástricos del animal (proceso denominado endozoocaria); es decir, la semilla necesita ser digerida por un animal y ser defecada para estar en condiciones de germinar. En la actualidad, este proceso se realiza en laboratorios para siembra controlada y planificada; pero en este caso la siembra se verificó en condiciones naturales.

\section{POTENCIAL ECONÓMICO}

El potencial a aprovecharse es muy significativo desde el punto de vista económico, si se respeta el nuevo bosque y no se lo depreda. Se estima que cada árbol adulto produce en promedio cien kilos (en cifras muy conservadoras) de vainas (sin considerar la goma hiperlipidemia, de uso en diversos fármacos para reducir los niveles de colesterol, por ejemplo) anualmente, por lo que si lograran sobrevivir y llegar a la etapa de producción cien plantas por hectárea, que es lo recomendable forestalmente, tendríamos un bosque de estratos adultos compuesto por 8 millones de unidades, pudiendo industrializarse 800000 toneladas de vainas a un costo de 160 millones de nuevos soles. Y si se quisiera criar animales, permitiría brindar raciones diarias para 20 mil cabezas de ganado al año, conservadoramente hablando.

\section{DISCUSIÓN}

Esta realidadnosplantea nuevasinterrogantes. Consideremos que toda investigación que se concluye, descriptiva o no, genera preguntas nuevas que orientan las siguientes etapas de la investigación. He aquí algunas de estas interrogantes: ¿tienen ciclos de vida los desiertos del norte costeño?, ¿qué duración tiene el bosque desde que se inicia hasta que muere?, ¿qué tiempo de silencio de vida existe desde que fenece el bosque hasta que se inicia el nuevo proceso de forestación natural?, ¿podemos conservar el bosque con un manejo sostenible?, ¿hay alguna oportunidad de aprovechar la actual laguna como recurso agrícola?, ¿se trata solo de un hipo de la naturaleza?, ¿cómo actuar orgánicamente frente a este evento?, ¿qué participación corresponde a los pobladores del lugar? 
Gráfico 1. Ubicación de la Depresión Bayóvar. (Mapa Físico-Político)

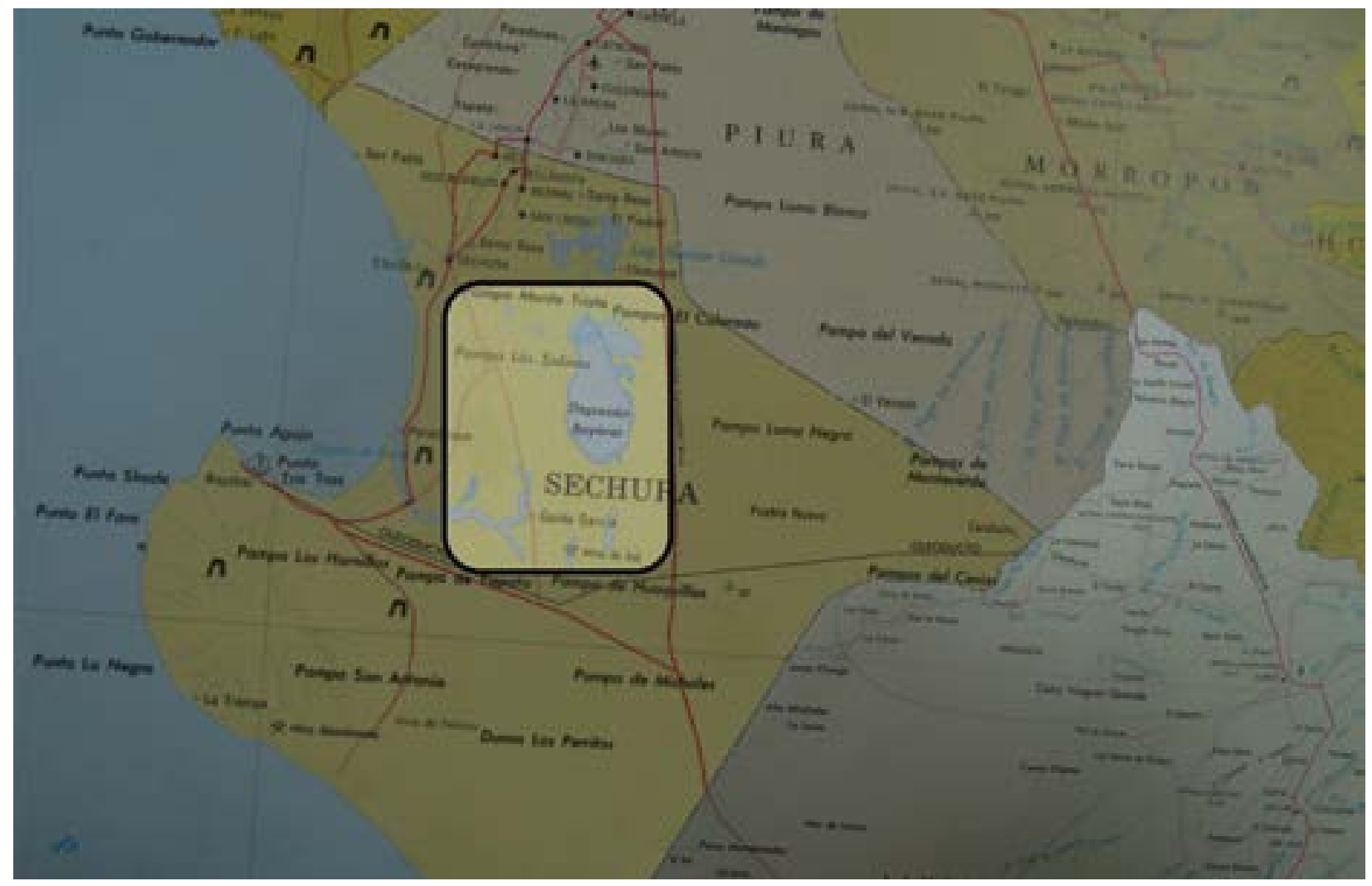

Gráfico 2. Vista satelital Google de la laguna Sechura, 2009

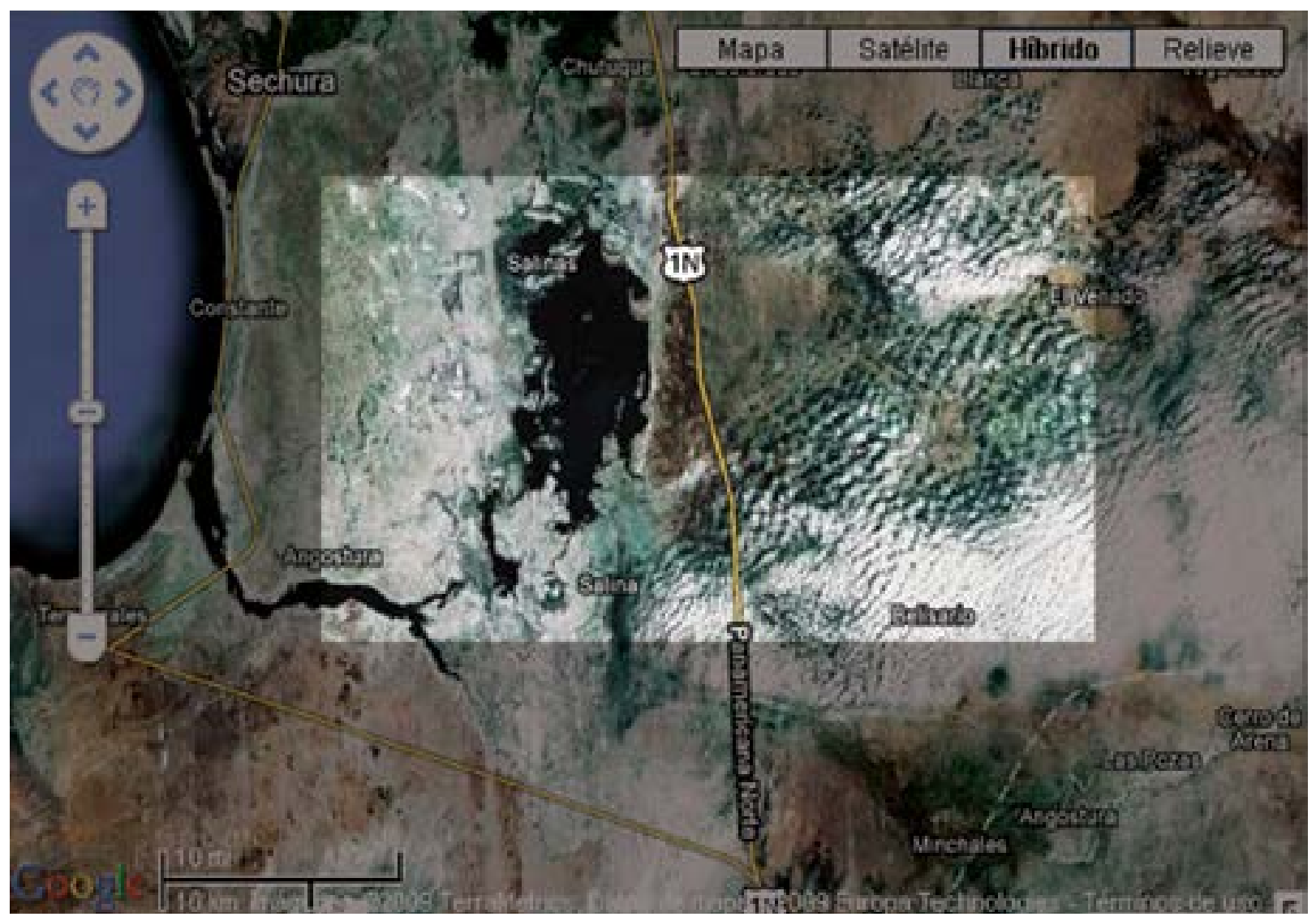




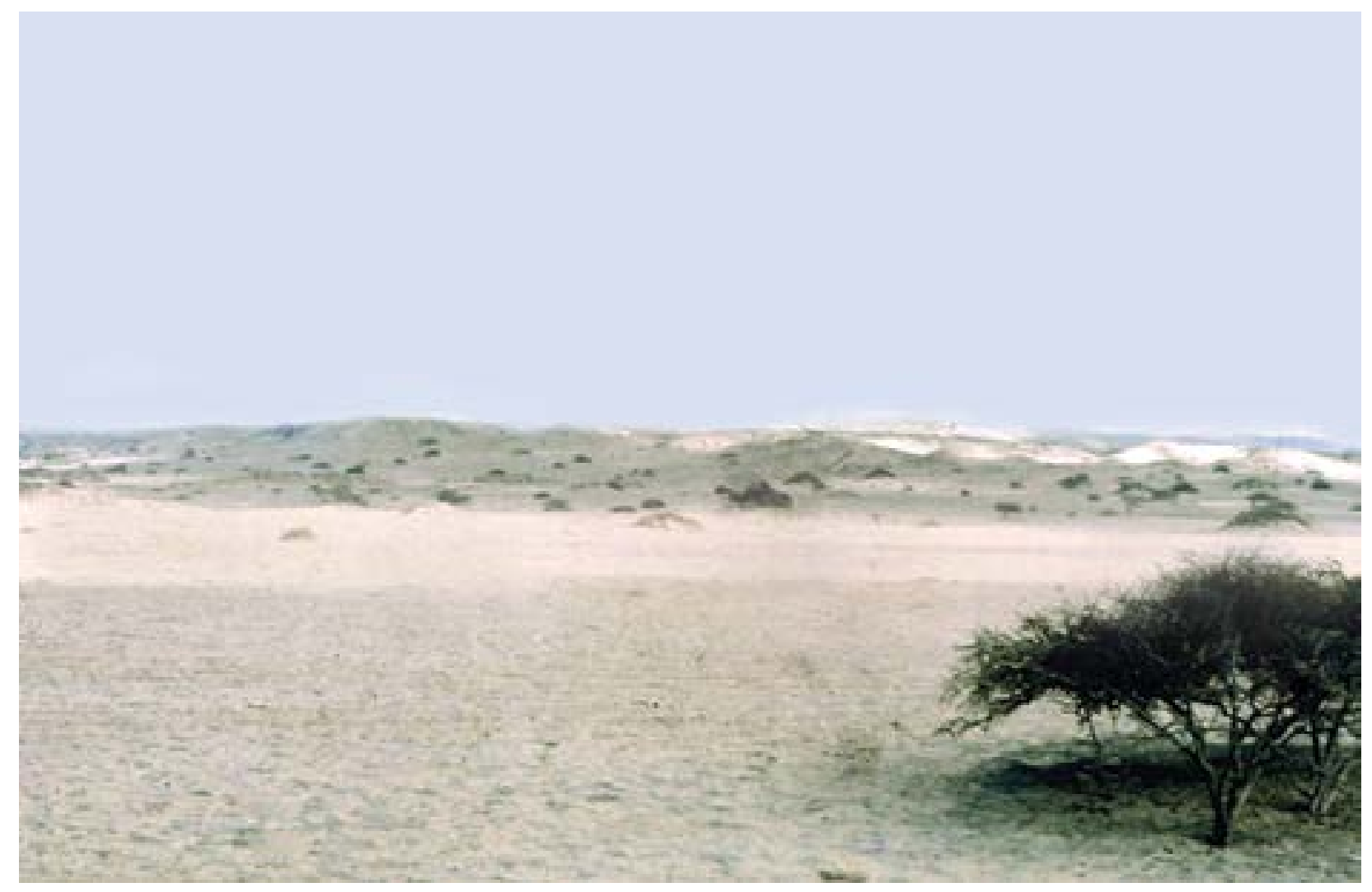

Fotografía 1. Pampa de San Antonio. Desierto de Sechura, 1978

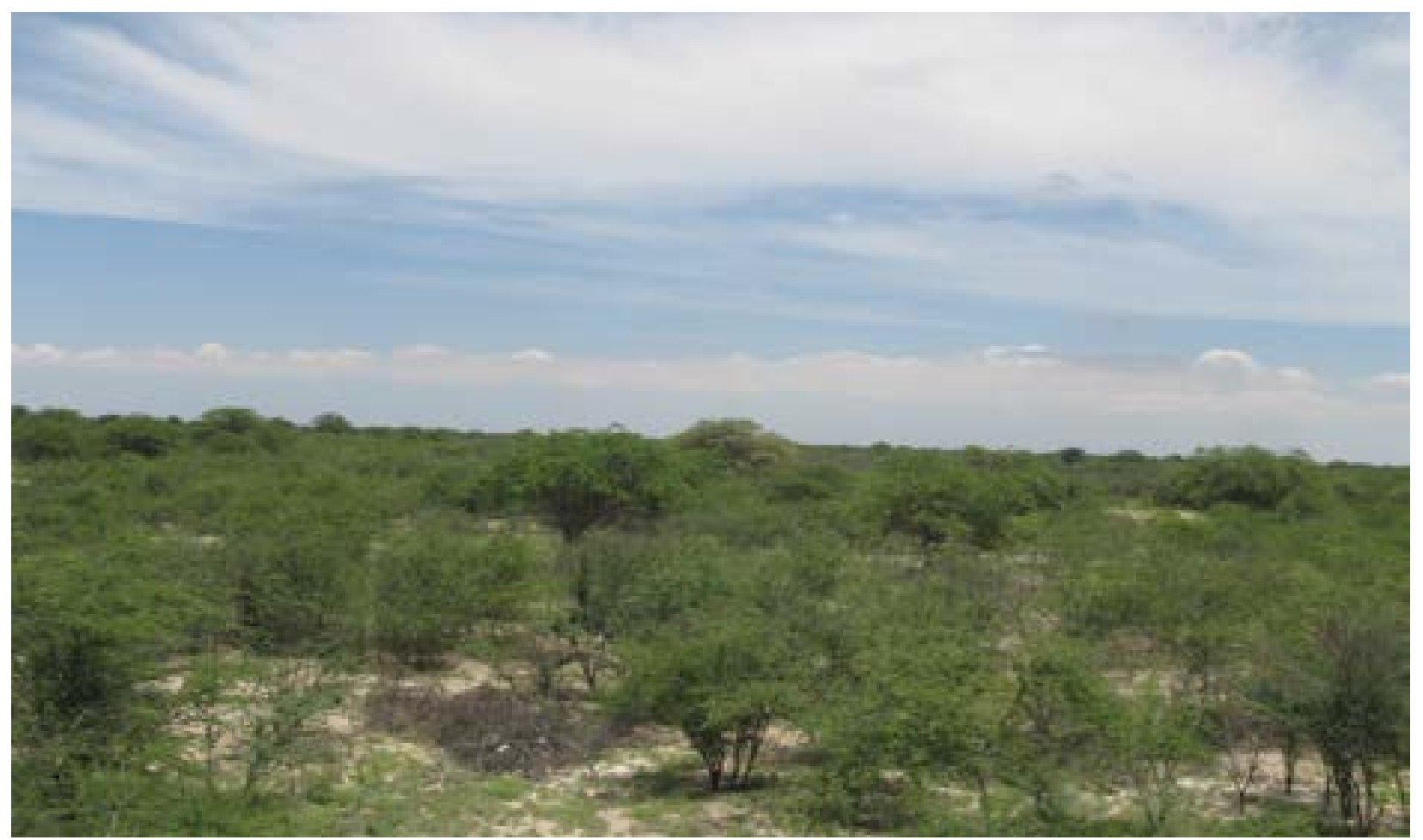

Fotografía 2. Pampa de San Antonio, 2010 


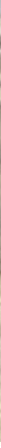

Fotografía 3. Segmento Este de la Laguna de los Flamencos. Sector entre Médano Grande y Chocol.

9 de septiembre de 2010

Fotografía 4. Bandada de flamencos. Laguna de los Flamencos, sector Médano Grande.

18 de octubre de 2009. 11.00 a. m. 

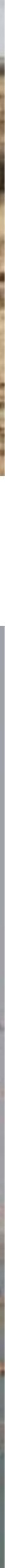


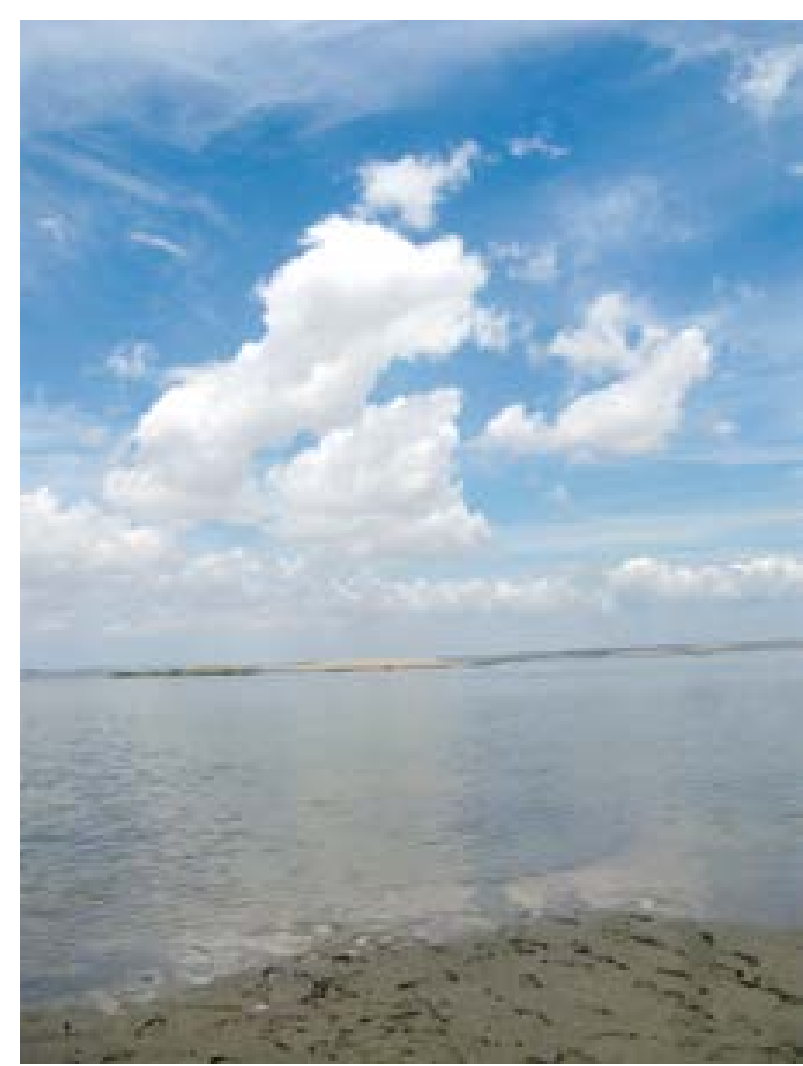

Fotografía 5. Segmento de la Laguna de los Flamencos. Médano Chico. Marzo de 2009

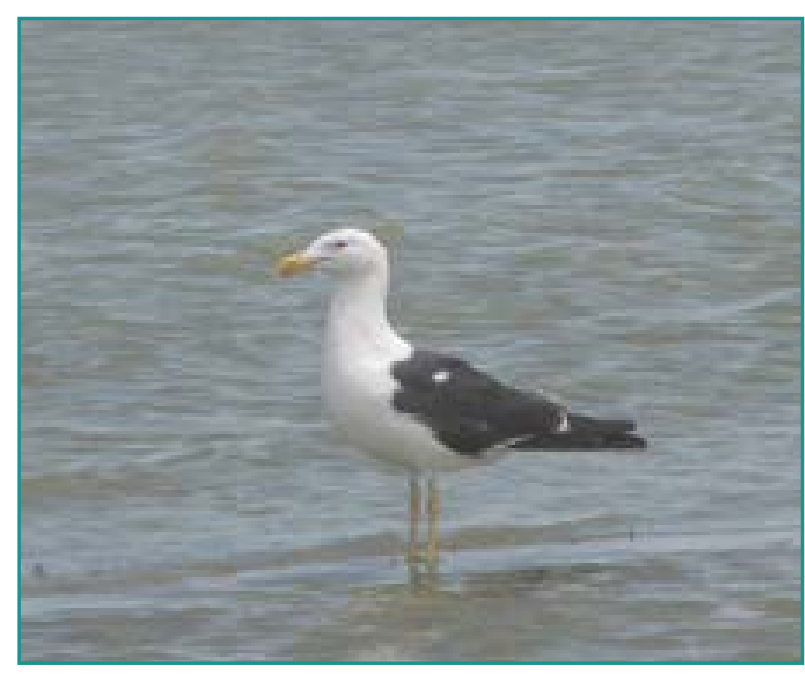

Fotografía 8. Gaviota dominicana (Larus dominicanus)

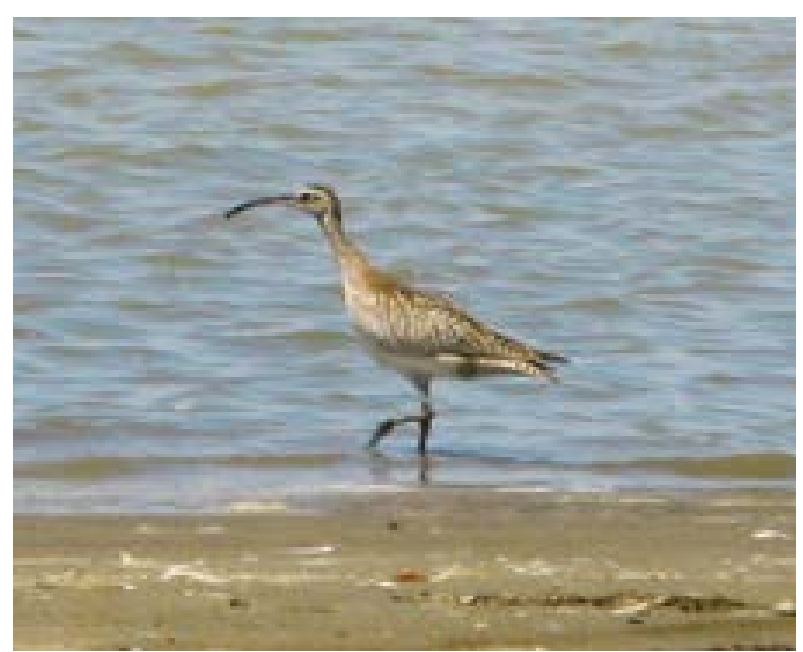

Fotografía 6. Sarapito trinador (Numenius phareopus)

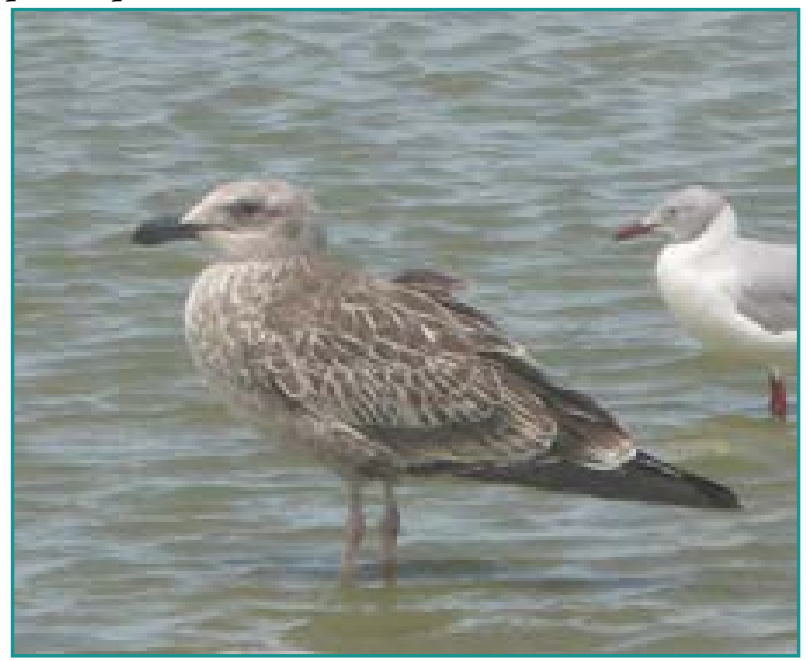

Fotografía 7. Gaviota juvenil (Larus

dominicanus). Los especímenes juveniles se diferencian por el pico negro.

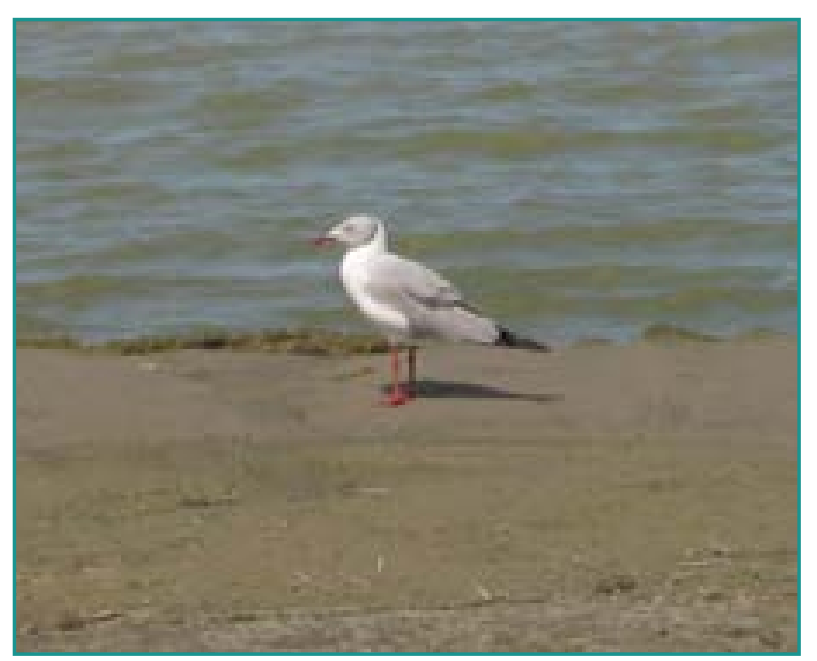

Fotografía 9. Gaviota gris (Larus cirrocephalus) 


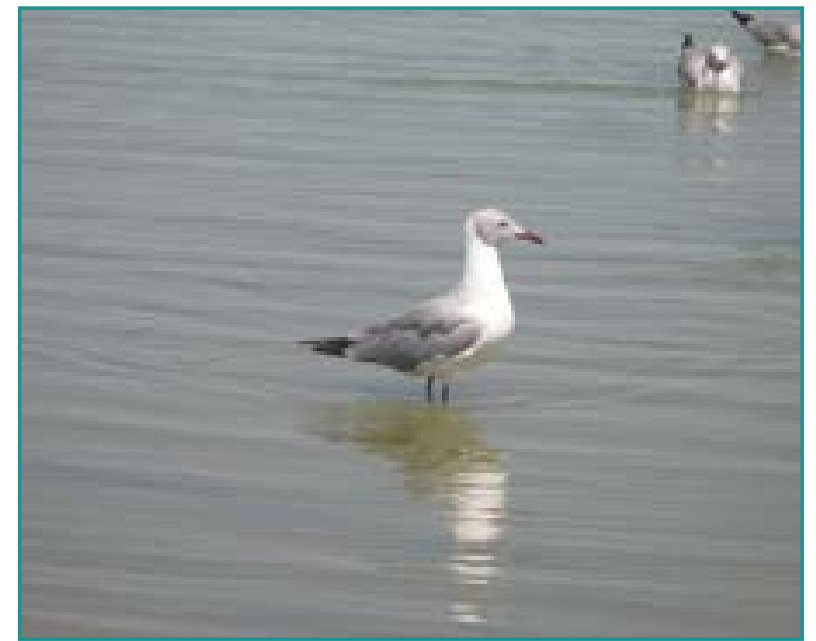

Fotografía 10. Gaviota peruana (Larus velcheri)

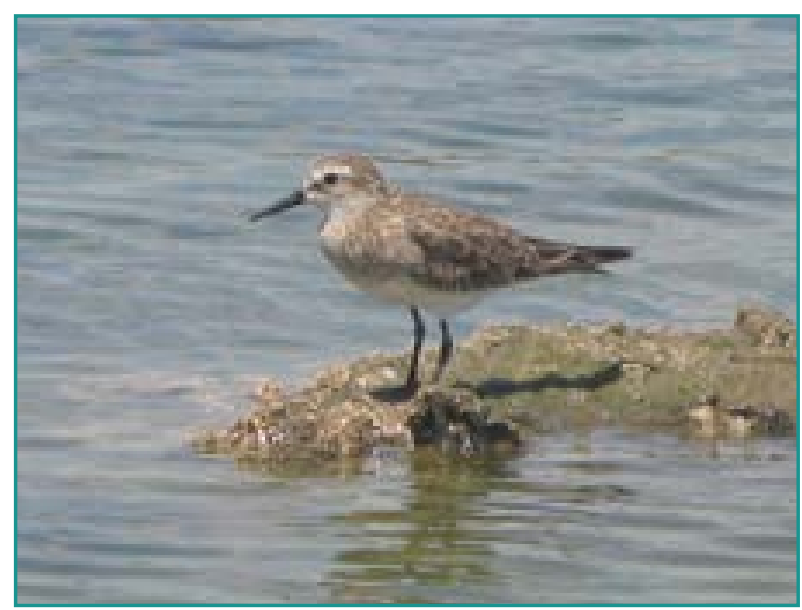

Fotografía 12. Playerito (Calidris mauri)

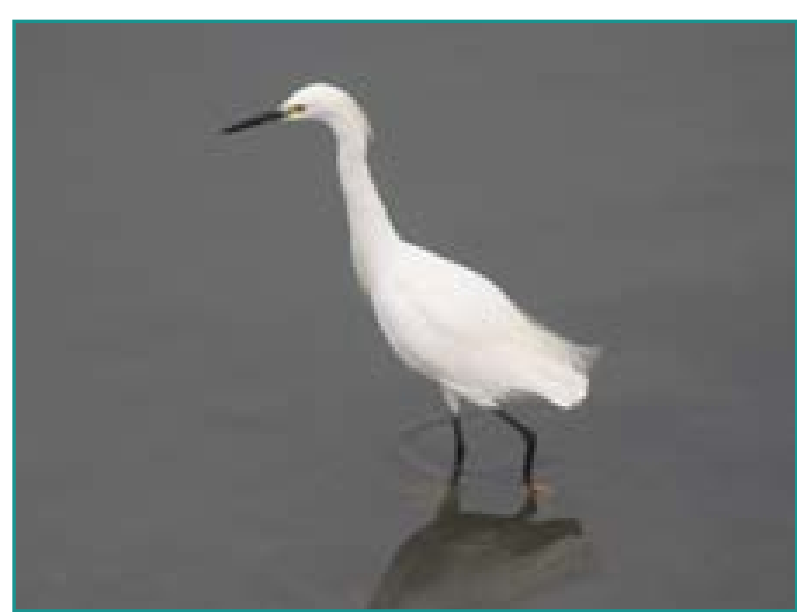

Fotografía 14. Garza blanca (Egretta thula)

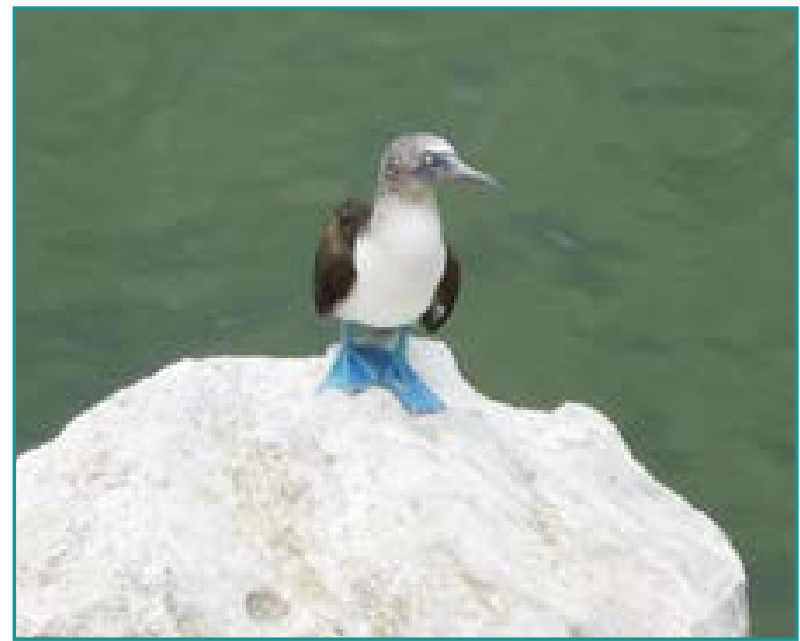

Fotografía 11. Piqueros (Sula variegata)

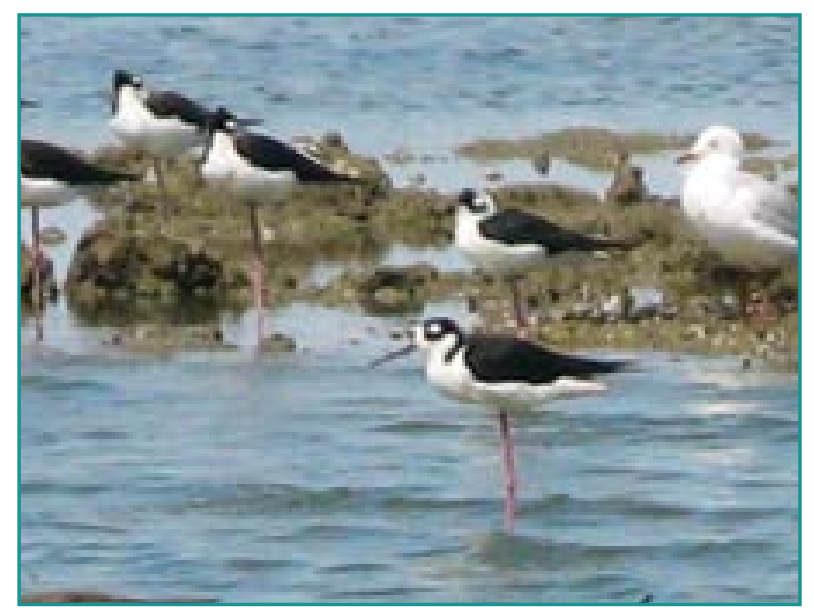

Fotografía 13. Cigüeñuela (Himantopus mexicanus)

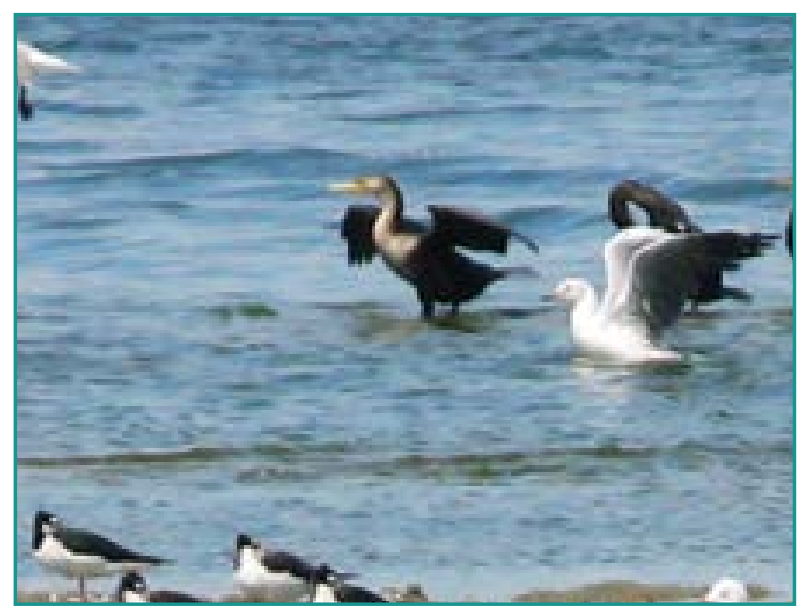

Fotografía 15. Cormorán (Phalacrocorax brasilianus) 


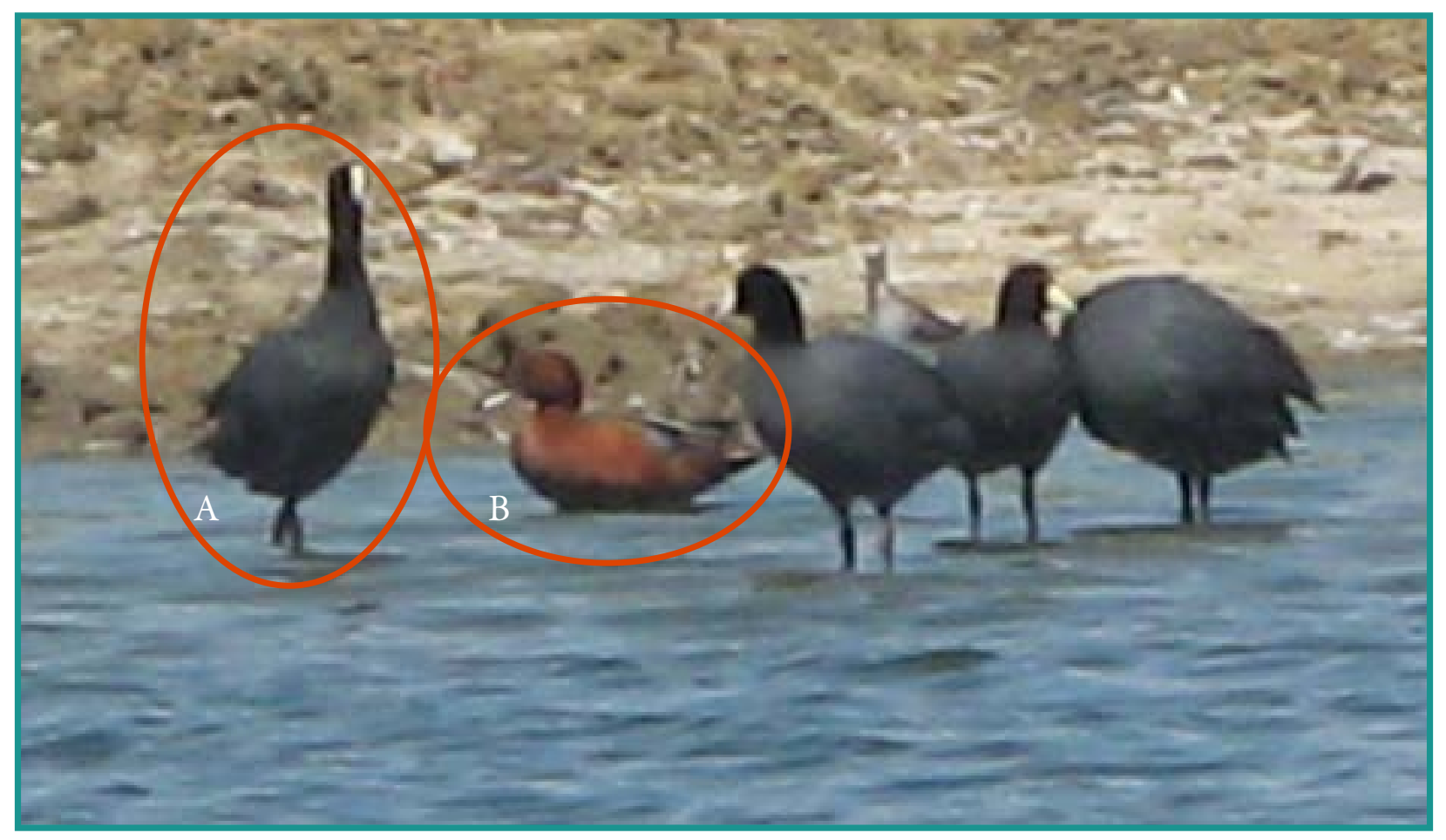

Fotografía 16. A) Gallareta andina (Fulica ardesiaca), B) Pato colorado (Anas cyanoptera)

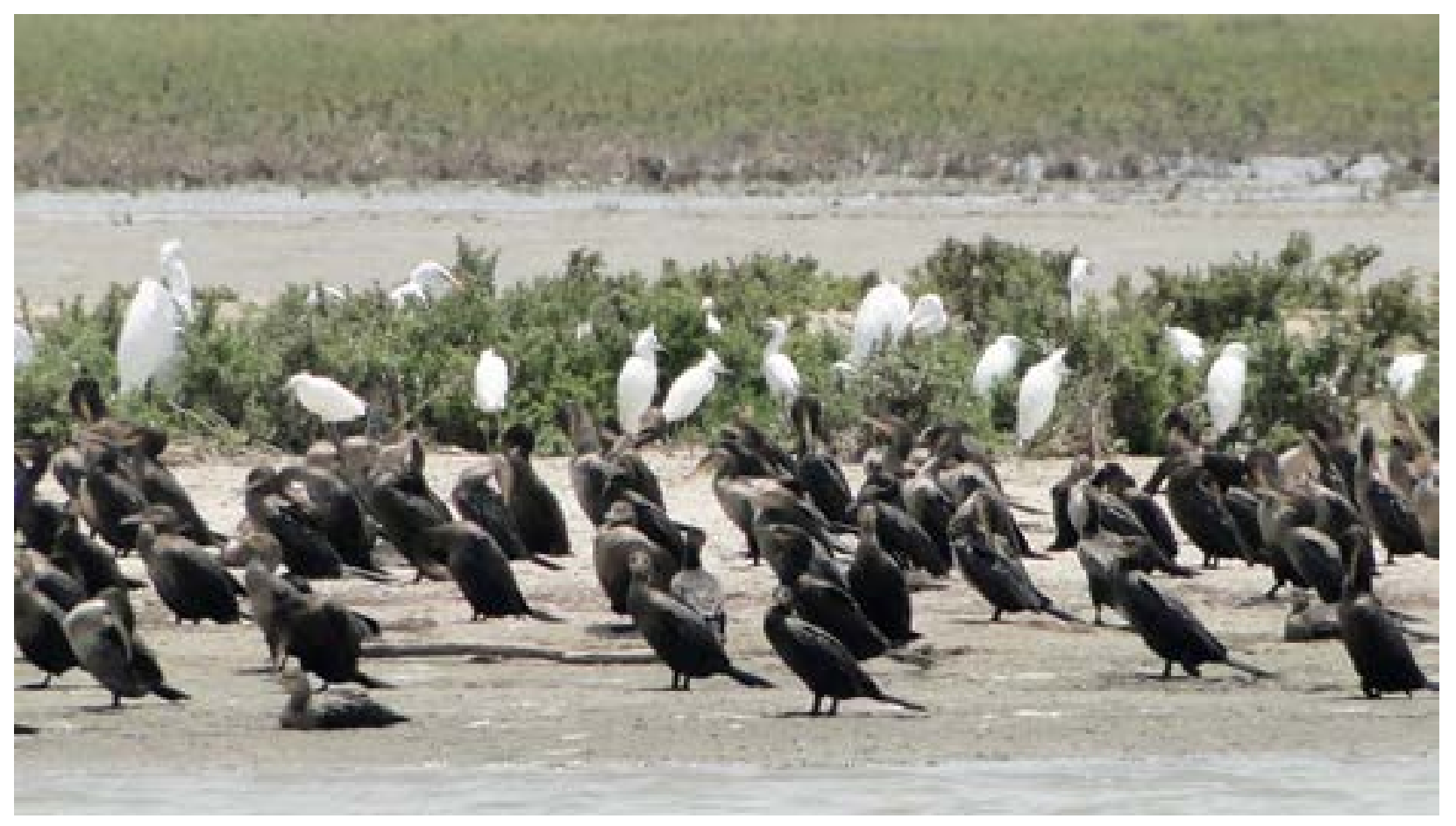

Foto 17. Nidos de aves, cormoranes y garzas 


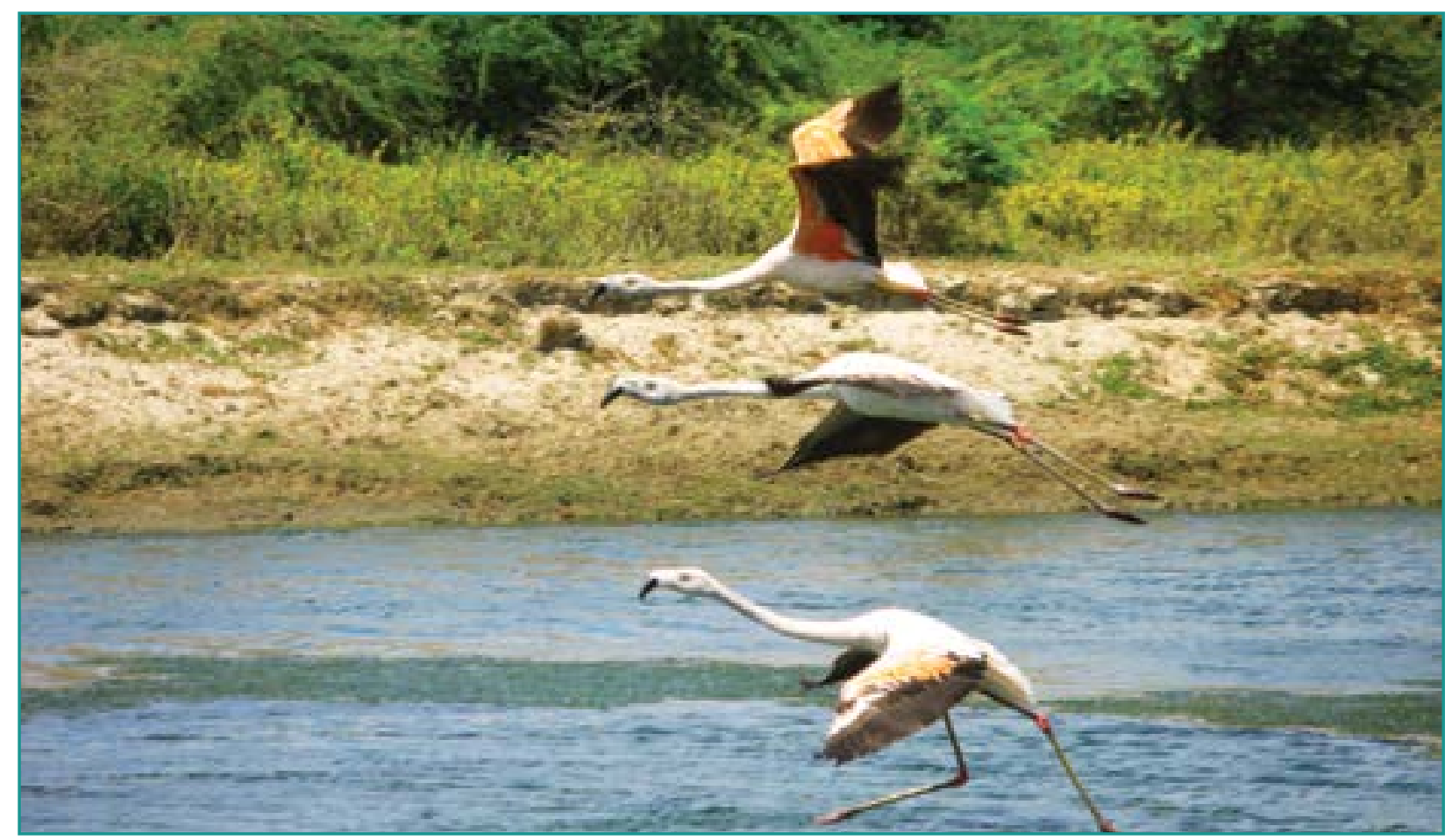

Fotografía 18. Flamencos (Phoenicopterus chilensis)

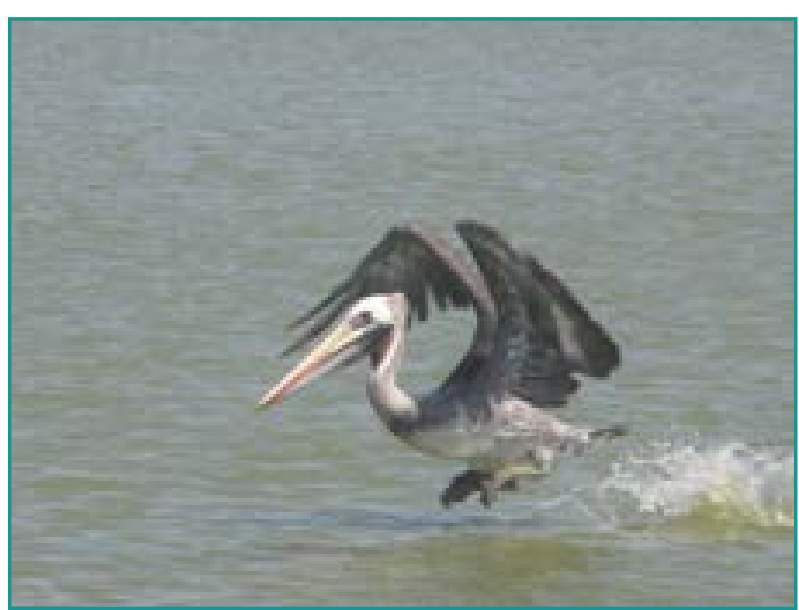

Fotografía 19. Pelícano peruano (Pelecanus thagus)

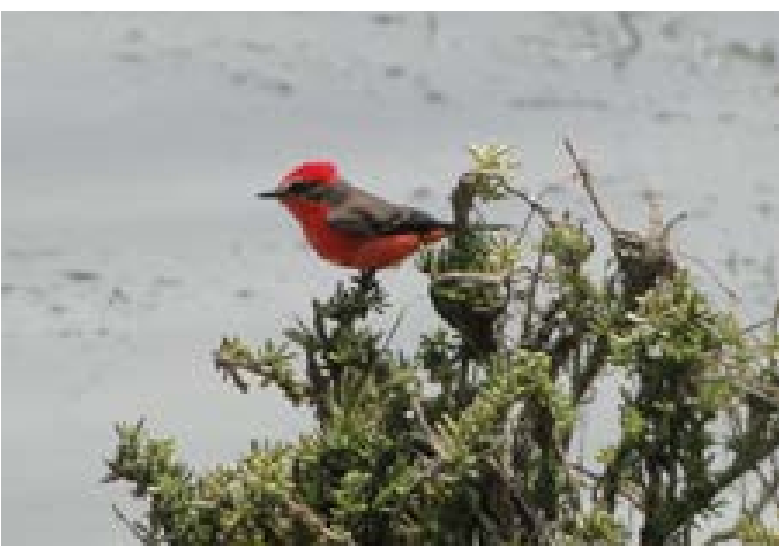

Fotografía 21. Putilla (Pyrocephalus rubinus)

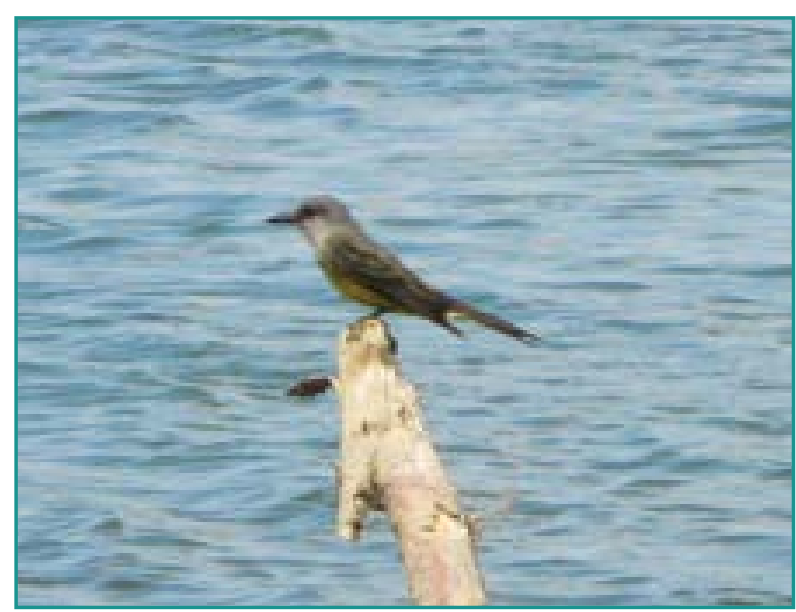

Fotografía 20. Avispero, tirano tropical (Tyrannus melancholicus)

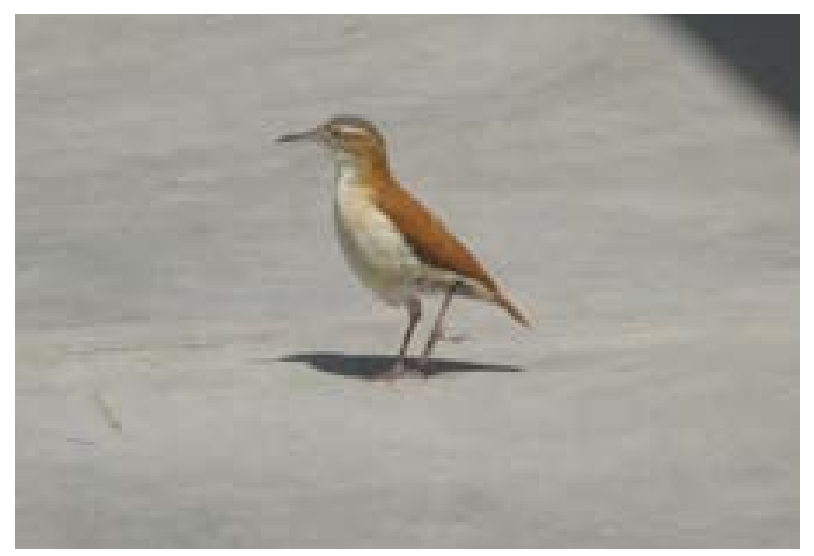

Fotografía 22. Chilalo (Furnarius leucopus)

CIEN DES 12 -2010 


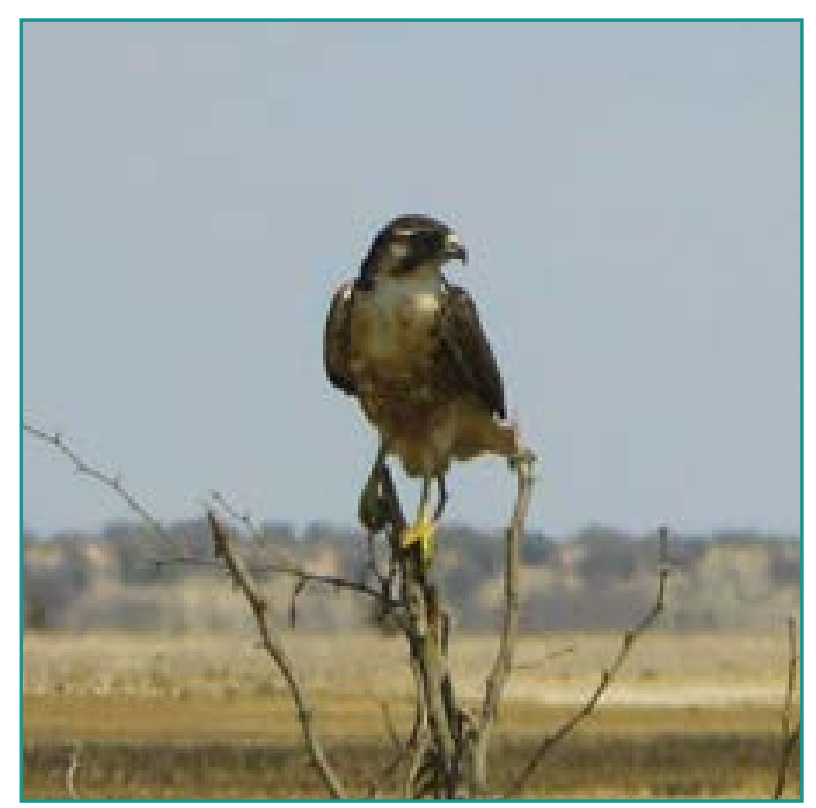

Fotografía 23. Gavilán (Accipiter nisus)

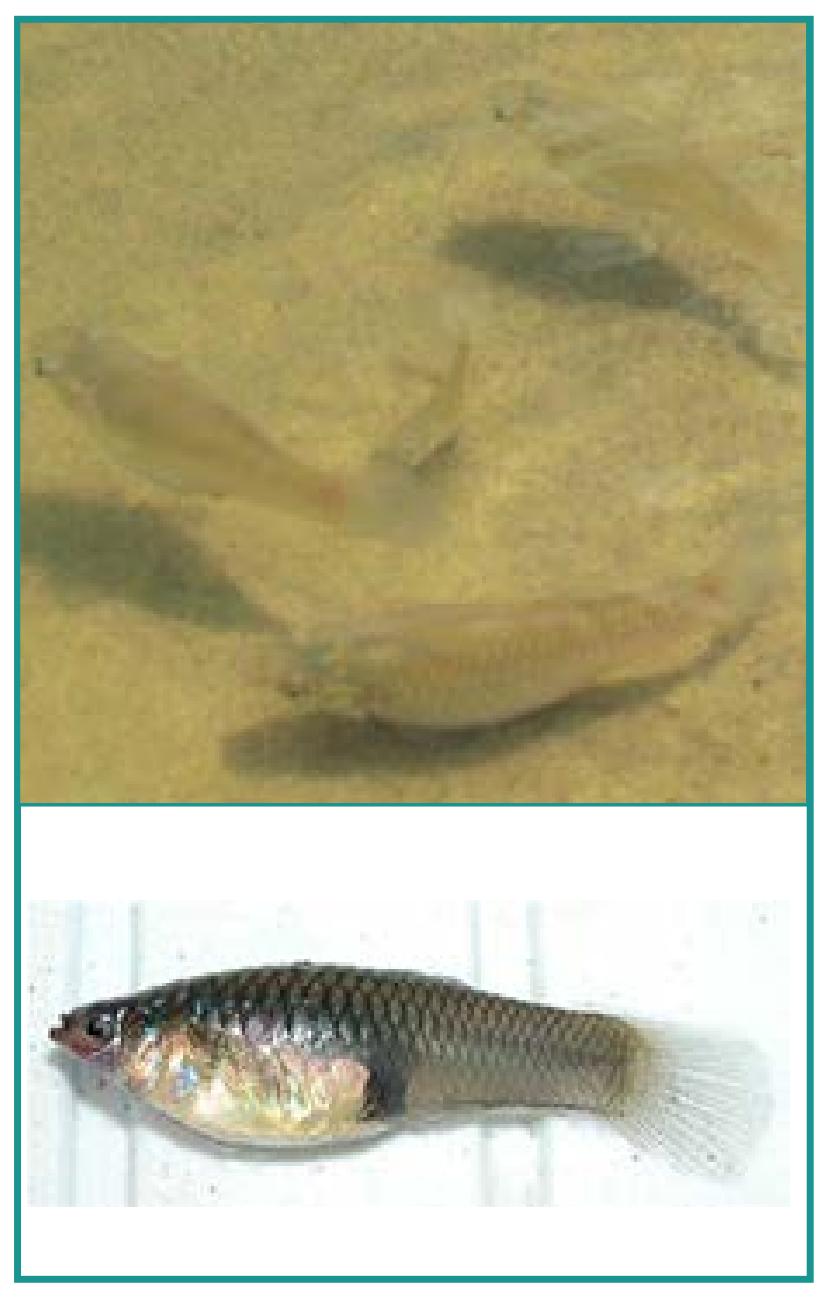

Fotografía 25. Guppy (Poecilia reticulata)

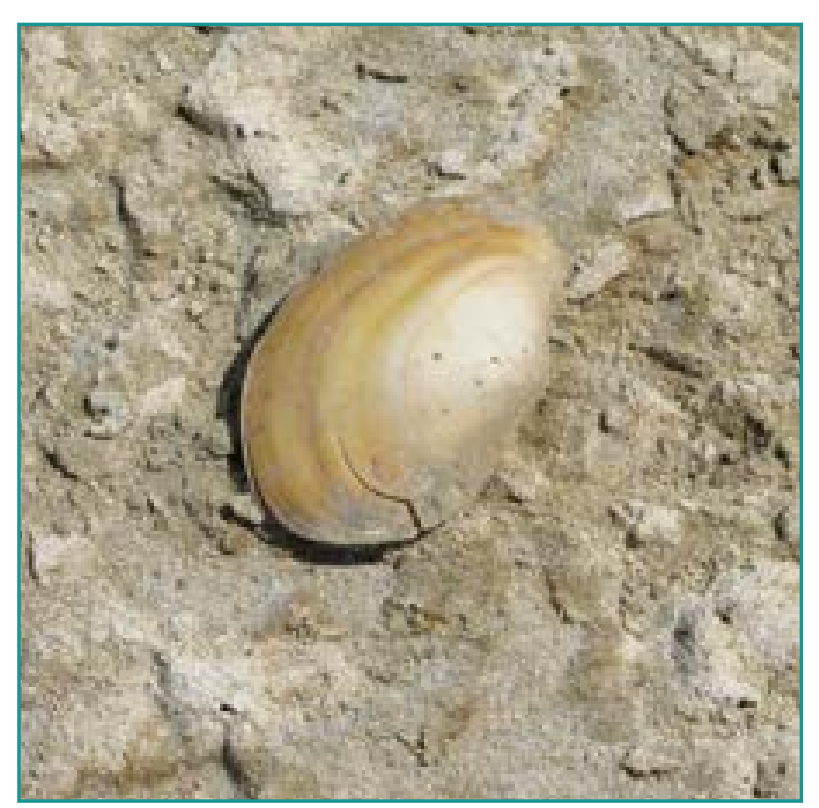

Fotografía 24. Almeja de agua dulce (Anodonta anatina)

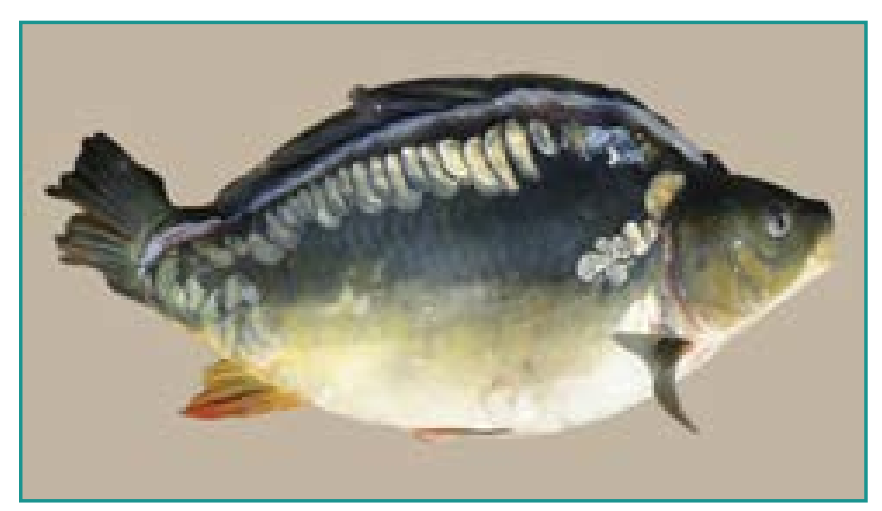

Fotografía 26. Carpa (Cyprinus carpio)

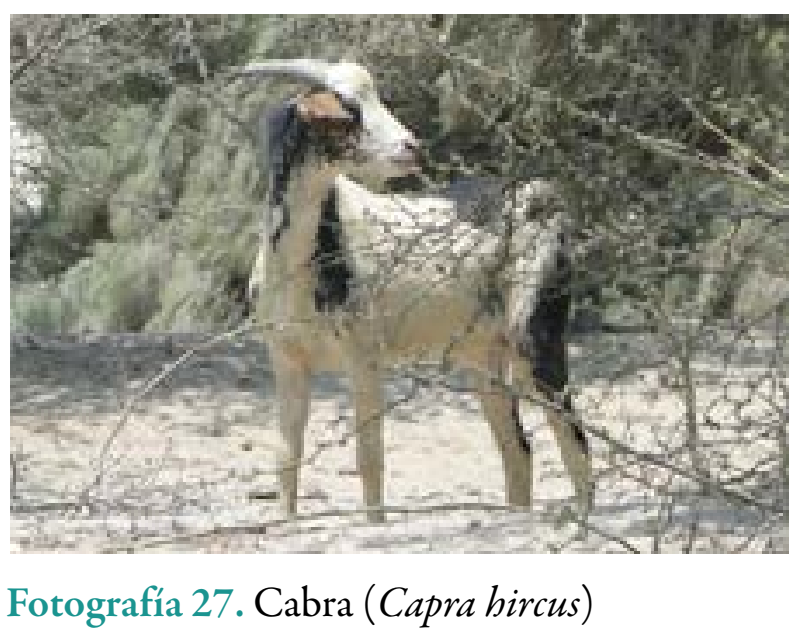




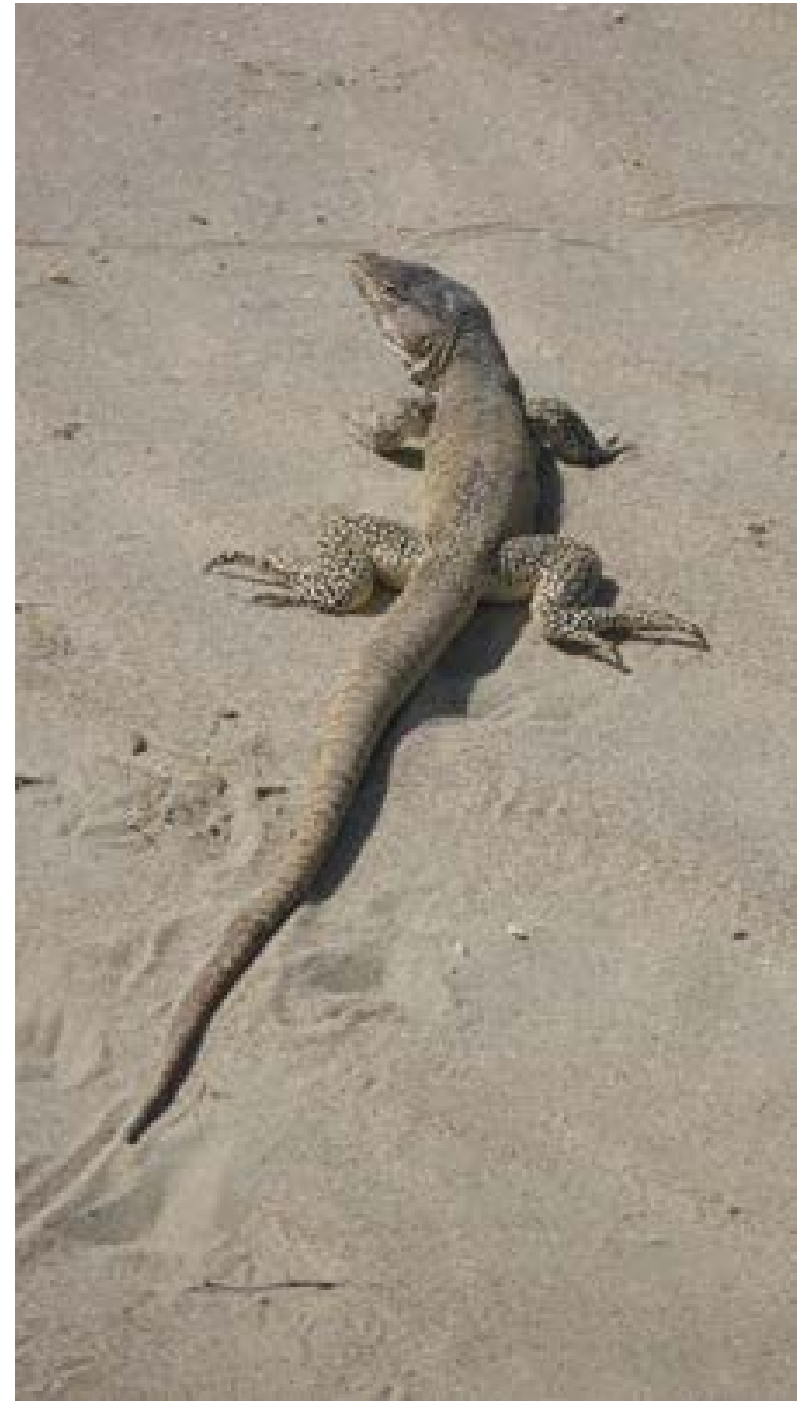

Fotografía 28. Iguana (Callopistes flavipuntatus)

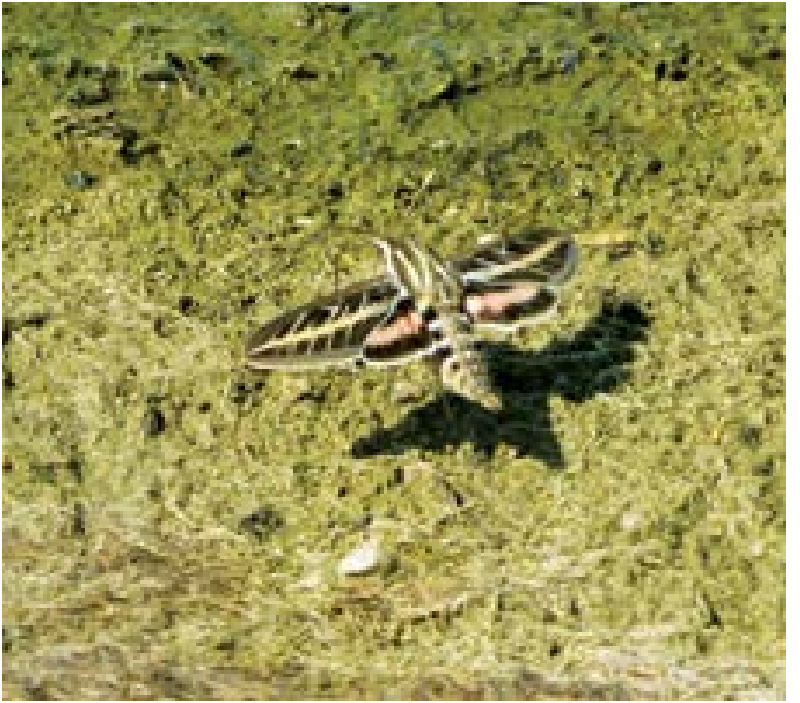

Fotografía 29. Mariposa

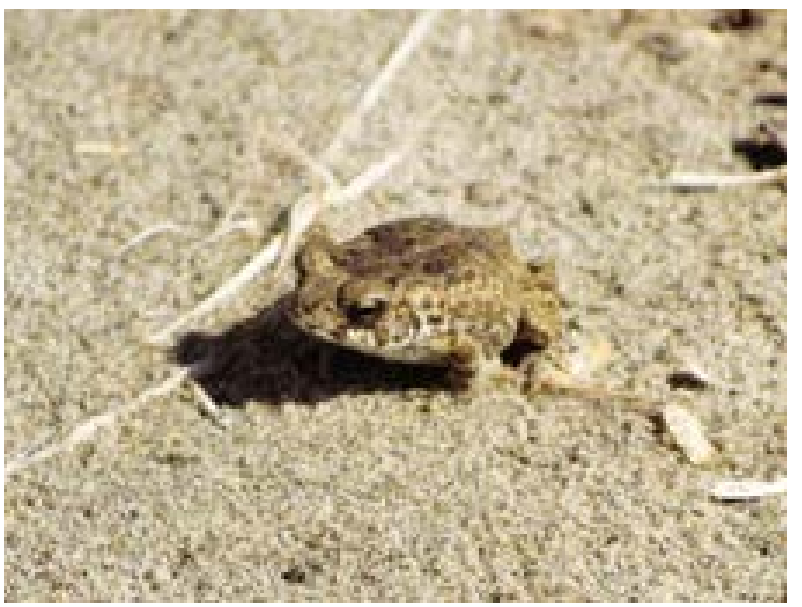

Fotografía 30. Sapo cololo (Bufonidae sp.)

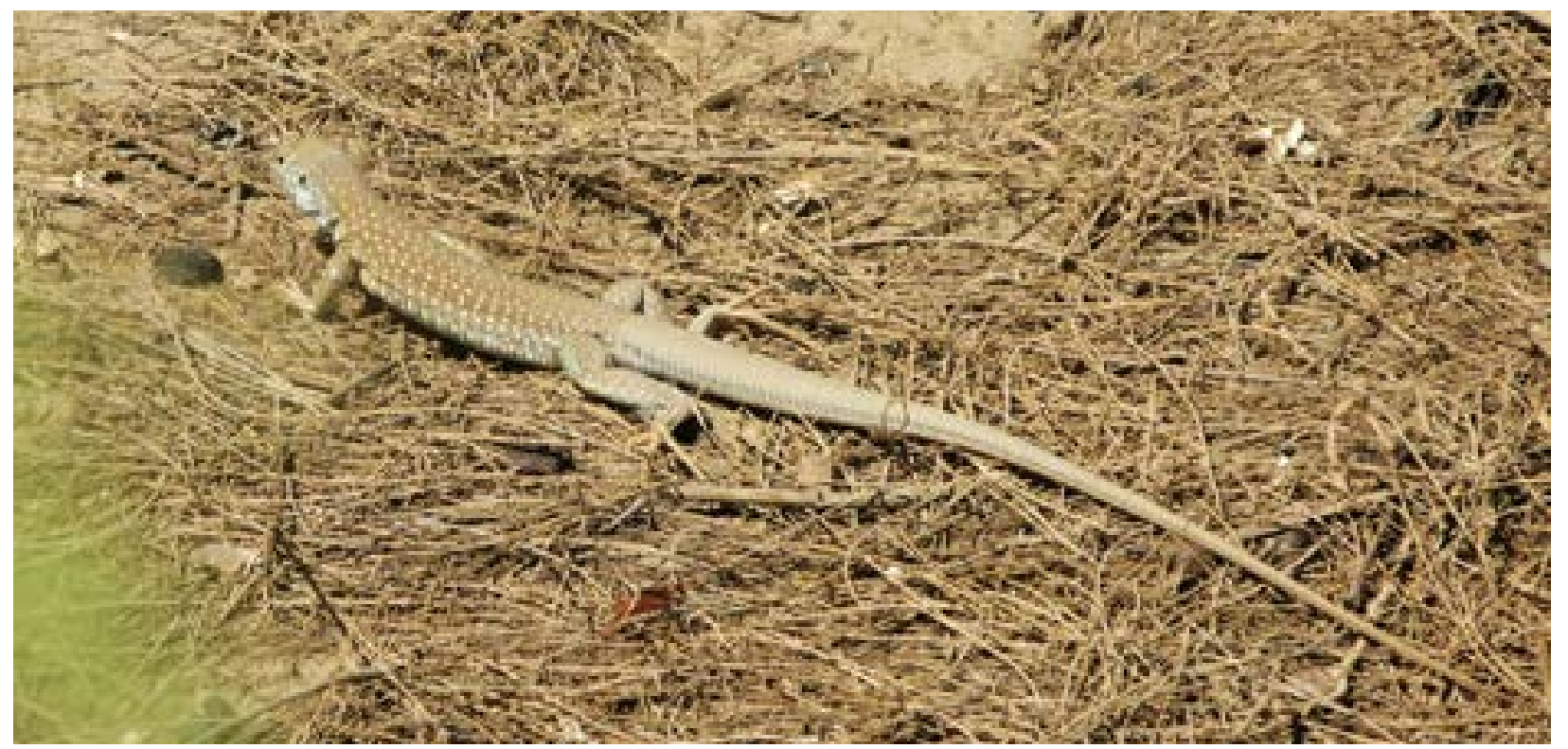

Fotografía 31. Cañán (Dicrodon guttulatum) 


\section{REFERENCIAS BIBLIOGRÁFICAS}

1. Alcócer, Francisco (1578). 1987. Probanzas deindiosyespañoles referentes a las catastróficas lluvias de 1578, en los corregimientos de Trujillo y Saña. Versión paleográfica y comentarios de Lorenzo Huertas Vallejos. CES Solidaridad, Chiclayo.

2. Bellido, Eleodoro. 1970. "Mapa Geológico del Perú". Artículo incluido en el Atlas Histórico-Geográfico y de Parques Peruanos. Lima, Perú. pp. 117-119.

3. Bernex de Falen, Nicole. 1987. La Geografía Regional del Norte. CIPCA. Lima, Perú. 120 pp.

4. Brack Egg, Antonio; Mendiola Vargas, Cecilia. 2004. Ecología del Perú. Editorial Bruño. Lima, Perú. 498 pp.

5. Caldas, Julio; Palacios, Óscar; Pecho, Víctor y Vela, Churchill. 1980. "Geología de los cuadrantes de Bayóvar, Sechura”. Instituto Geológico Minero y Metalúrgico. Boletín 32, Serie A. Carta Geológica Nacional. Mayo, Lima, Perú.

6. Cárdenas, Mercedes; Huapaya, Cirilo; Huapaya, Blanca; Deza, Jaime. 1981. Arqueología del Macizo de Illescas. Pontificia Universidad Católica del Perú. Lima, Perú. 210 pp.

7. Colegio de Ingenieros del Perú. 1998. Informe del Fenómeno del Niño 1997 - 1998. Lima, Perú

8. Deutscher Entwicklungsdienst. Oct. 2005. Estudio de caso: Declaración y plan de acción ambiental de la provincia de Sechura. Foro Ciudades para la Vida. Sechura, Piura, Perú. $125 \mathrm{pp}$.

9. Deza Rivasplata, Jaime. 2001. ¿Se seca la costa? Fondo Editorial de la Universidad Alas Peruanas. Lima, Perú. 120 pp.

10. Deza Rivasplata, Jaime. 2007. El agua de los incas. Fondo Editorial de la Universidad Alas Peruanas. Lima, Perú. 180 pp.
11. Deza Rivasplata, Jaime. 2010. Metodología de la investigación cientifica. Fondo Editorial de la Universidad Alas Peruanas. 3ra. edición. Lima, Perú. 200 pp.

12. Eche Morales, Justo; Amaya Chapa, Emeregildo. 1998. La "Niña" de Sechura. Bol. Sechura, mayo. Piura, Perú.

13. Engel, Frederic. 1982. Las Lomas de Iguanil. Centro de Investigación de Zonas Áridas. Universidad Agraria La Molina. Lima, Perú. $110 \mathrm{p}$.

14. Gobierno Regional de Piura. Plan estratégico de la Babia de Sechura y la isla de Lobos de Tierra - Diagnóstico. Gerencia Regional de Manejo Integrado de Recursos de la Zona Marino-Costera de Piura. Piura. Enero 2005.

15. Instituto Geográfico Nacional. 1989. Atlas del Perú. Proyecto Especial Atlas del Perú. Ministerio de Defensa.

16. Instituto Geográfico Nacional. 1995. Mapa Físico-Politico del Perú.

17. Milla Villena, Carlos. 1989. Inventario de un desierto. Pontificia Universidad Católica del Perú. Lima, Perú. 150 pp.

18. Novoa Goicochea, Zaniel. 1998. Las lagunas de Las Salinas. Pontificia Universidad Católica del Perú. Lima.

19. Petersen, Georg. 1956. Estudios climatológicos en el Noroeste peruano. Boletín Sociedad Nac. de mineria y petroleo n ${ }^{\circ 49}$. Lima, Perú

20. Ramírez Prado, Fidel; Deza Rivasplata, Jaime. 2000. Cuando los desiertos eran bosques. Fondo Editorial de la Universidad Alas Peruanas.

21. Tume Ruiz, Juan M. 1999. Evaluación biológica pesquera de la laguna La Niña (Piura - Lambayeque). Tesis de Licenciatura en Ingeniería Pesquera. Universidad Nacional de Piura. Facultad de Ingeniería Pesquera, Departamento Académico de Ciencia y Tecnología de la Pesca. 